\title{
The flushing flow problem: Defining and evaluating objectives
}

\author{
G. Mathias Kondolf \\ Department of Landscape Architecture, University of California, Berkeley
}

Peter R. Wilcock

Department of Geography and Environmental Engineering, Johns Hopkins University, Baltimore, Maryland

\begin{abstract}
Reservoir releases may be specified for the purpose of maintaining or improving the downstream channel and habitat. A wide variety of ecological or management objectives may be defined for such flushing flows (which may be broadly divided into sediment maintenance and channel maintenance flows). To specify a particular discharge and water volume for a flushing flow requires that the ecological or management objectives be translated into specific physical objectives for which flows can be specified. Flushing objectives that cannot be translated into definable flows are of little practical use, regardless of their intrinsic importance. Once defined, flushing flow objectives may be shown to conflict in some cases. For example, no flushing flow can satisfy the typical sediment maintenance objectives of maximizing sand removal and minimizing gravel loss. A discharge that mobilizes sediment throughout the channel cross section for channel maintenance purposes will often produce comparable transport rates of sand and gravel, thereby eliminating the selective transport of sand needed to reduce the sand content in the bed. Some nonflushing alternatives, such as artificial gravel replenishment and pool dredging, can be used to improve the performance of flushing flows. Selection among these alternatives and specification of a flushing flow discharge and volume depend directly on quantitative estimates of sand and gravel transport as a function of flow rate and volume.
\end{abstract}

\section{Introduction}

River channels immediately downstream of reservoirs typically experience a decrease in flood flows and sediment supply. When flow diversions are made at the reservoir, the total discharge is also reduced. When a natural discharge regime is replaced by a low constant discharge, portions of the channel no longer inundated by high flows are lost as aquatic habitat. The variability of topography, depth, and velocity in the channel may decrease with the loss of natural flow variability. Beyond these direct hydrologic effects, reservoir regulation can affect aquatic habitat through adjustments in channel geometry and sediment.

The adjustments of the downstream channel depend on the relative changes in flood magnitude, sediment transport capacity, both the load and caliber of sediment supply, and the rate at which unregulated water and sediment are introduced from tributaries downstream of the reservoir [Williams and Wolman, 1984]. If reservoir storage has sufficiently reduced the river's transport capacity, fine sediment introduced from downstream tributaries may accumulate on the bed. Reduced flood flows may also produce channel narrowing by depositing sediment along channel margins, abandoning multiple channels and adopting a single thread, incising a narrow channel within the formerly active bed, and colonizing vegetation of the formerly active channel.

To mitigate these dam-induced impacts, controlled flushing flow releases, designed to mimic the action of natural floods in Copyright 1996 by the American Geophysical Union.

Paper number 96WR00898.

0043-1397/96/96WR-00898\$09.00 removing accumulated sediments and scouring the channel, are commonly required in dam licenses [Milhous, 1982; Reiser et al., 1989] and increasingly proposed as components of riverine restoration programs [Hesse and Sheets, 1993]. Flushing flows constitute one component of instream flow requirements for maintenance of aquatic and riparian habitat. In the past, most attention to instream flow needs has centered around minimum flow requirements [Loar and Sale, 1984; Lamb and Doerksen, 1987], but with the importance of floods in maintaining the dynamic nature of riparian and aquatic ecosystems now widely recognized [Resh et al., 1988; Sparks et al., 1990; Gregory et al., 1991], flushing flows are more commonly required as well.

A variety of ecological and management objectives for flushing flows may be distinguished. These may be divided into either of two broad categories of sediment maintenance or channel maintenance, depending on whether they are designed to modify or maintain the channel sediment or the channel geometry. In addition to these objectives (which establish minimum flushing flows), maximum flushing flows may be determined by constraints imposed by flood control requirements, costs of water, and gravel loss from reaches where upstream gravel supply has been eliminated by dams (Tables 1 and 2).

Flushing flows may involve considerable costs such as lost power generation, reduced water supply, and loss of spawning gravels. Despite this, in many cases, flushing releases have been recommended without specific statements of flushing objectives or evaluation of whether those objectives are actually achievable. Instead, flushing flows are often presented in terms of one or more of the many flushing methods that have been proposed [Reiser et al., 1989], with insufficient consideration to whether the methods are appropriate or effective for the prob- 
lem at hand. In these cases the distinction between method and objective can become blurred, with the result that there may be little certainty that the flushing flows will produce a desirable result. Further, it has been shown that different flushing methods applied to the same stream can produce a wide range of calculated discharges [Kondolf et al., 1987; Milhous and Bradley, 1986] and therefore may produce a wide range of physical changes to the river channel. A meaningful estimate of flushing flows requires a clear statement of objectives, so that the flow necessary to achieve those objectives can be determined.

A further problem is that some flushing objectives are too broadly stated to admit specification of particular flushing flows. For example, requiring flows for "channel maintenance" without specifying the associated channel processes does not permit a useful discharge to be specified with any certainty. Flushing flows suitable for specific ecological goals may be difficult to specify, because the connections among hydraulics, sediment transport, and ecological response are complex and influenced by a variety of factors. Ecological objectives must be restated in terms of the physical changes (with presumed ecological benefits) that may be produced by a flushing flow. Flushing objectives that cannot be translated into definable flows are of little practical use, regardless of their intrinsic importance.

In this paper we attempt to restate various ecological and management objectives in terms of physical changes for which flushing flows may be defined. Having done this, some objectives can be recognized as incompatible. Achieving such diverse objectives may require nonflow alternatives, such as mechanical bank manipulation, artificial sediment supply, and pool dredging. Both the costs and risks associated with flushing flows can be quite large, so there is a clear need for a quantitative basis for choosing among the available options. Once flushing flow objectives are clearly defined, the necessary discharge and water volume may be specified, and thus costs, sediment transport, and channel change associated with each alternative can be estimated. Although there is uncertainty in these estimates, they provide a basis for evaluating the costs and relative benefits of flushing flow and nonflow alternatives.

\section{Methods for Prescribing Flushing Flows}

Although the focus of this paper is on flushing flow objectives, it is useful to provide background by briefly summarizing the various methods suggested for calculating flushing flows. Comprehensive reviews by Reiser et al. $[1985,1989]$ classified flushing methods based on their data and field work requirements. Flushing methods may also be classified based on their underlying assumptions [Kondolf et al., 1987]. We recognize three categories of methods for estimating flushing flows: selfadjusted channel methods, sediment entrainment methods, and direct calibration methods.

Self-adjusted channel methods base flushing flows on a statistic drawn from the predam flow regime, assuming that the channel has achieved some kind of equilibrium with the prevailing flow regime and sediment load and that all channels arrive at this state of adjustment with a discharge whose frequency of occurrence is similar from place to place. The concept of a dominant or channel-forming discharge pertains to the overall, mean behavior of rivers. However, the concept may apply poorly to a particular channel because the assumption of equilibrium may not be valid, and because the effective discharge for that channel may not correspond to the generaliza- tions in the literature. Methods based on self-adjustment of channels include those that prescribe $200 \%$ of the mean annual flow [Tennant, 1976], the flow exceeded $17 \%$ of the time (T. M. Hoppe and R. A. Finnell, unpublished report, 1970), and the flow with a preregulation recurrence interval of 1.5 years [Montana Department of Fish, Wildlife, and Parks, 1981].

Sediment entrainment methods involve estimation of discharges at the threshold of gravel motion. Because some gravel transport is necessary for flushing, such methods provide a reasonable surrogate for flushing [Reiser et al., 1985; Milhous, 1990]. While these methods have an empirical basis, they are more general than self-adjusted channel methods because they may be based on the existing system: the channel, its sediment, and its hydraulics, which need not be in any state of adjustment. Observations of local properties (channel size and slope, bed material size) are used to estimate entrainment conditions without calibration.

Direct calibration methods involve observations of bed movement, sediment transport, or changes in fine sediment content of bed gravels. Observation of tracer gravel entrainment was used by Hey [1981], and computation of effective discharge from flow records and sediment rating curves was used by O'Brien [1987]. Direct calibration sidesteps the difficult task of predicting the discharge producing entrainment or fines removal, but requires site-by-site field work.

Neither the self-adjusted channel nor sediment entrainment methods includes estimates of the quantity of sand and gravel transported during a flush, upon which an evaluation of different flushing alternatives and release duration must be based. Such estimates may be included as part of a direct calibration estimate of flushing flows if transport rates and flushing effectiveness are evaluated [Wilcock et al., 1995].

\section{Existing (Old) and New Dams}

In making comparisons among flushing objectives, it is important to distinguish between new dams, where the river channel will experience flow and sediment regulation for the first time, and old dams that have been in place long enough to have induced channel adjustments. For new dams the flushing objectives may be stated in terms of maintaining certain aspects of the existing channel, such as active channel width (although they need not be; see work by Milhous and Bradley [1986]). In these cases, methods based on natural hydrographs may be suitable if sufficient water is available under project conditions.

For old dams, however, the river channel may already have adjusted to the reservoir-regulated flow regime. Methods based on natural hydrographs or channel geometry no longer provide a suitable basis for prescribing a flushing discharge because these methods implicitly assume a mutual adjustment among the hydrology, channel geometry, and sediment transport. The channel of an existing project will reflect an artificial and often incomplete adjustment between sediments in the channel before regulation and the supply of water and sediment after regulation. For example, a wide gravel-bedded river may have evolved into a narrower channel with steep, finegrained banks colonized by mature riparian vegetation, and the bed material may be finer or coarser owing to bed aggradation or degradation.

The range of feasible flushing objectives below existing dams may be constrained by the degree of postdam channel adjustments and limitations from release capacity, water and power 
Table 1. Potential Flushing Flow Objectives

\begin{tabular}{lll}
\hline \multicolumn{1}{c}{$\begin{array}{c}\text { Ecological or Management } \\
\text { Objectives }\end{array}$} & \multicolumn{1}{c}{ Specific Objectives } & Flow Requirements \\
\hline Restore/enhance riffle habitat & $\begin{array}{l}\text { remove surficial fine sediment } \\
\text { remove interstitial fine sediment } \\
\text { maintain gravel "looseness" }\end{array}$ & $\begin{array}{l}\text { mobilize sand } \\
\text { mobilize gravel } \\
\text { mestore/enhance pool habitat }\end{array}$ \\
$\begin{array}{l}\text { Maintain active channel width and } \\
\text { topographic diversity }\end{array}$ & $\begin{array}{l}\text { scour accumulated fine sediments } \\
\text { prevent encroachment of vegetation by } \\
\text { uprooting seedlings }\end{array}$ & $\begin{array}{l}\text { transport net sand out of pools } \\
\text { mobilize gravel throughout cross } \\
\text { Create/build floodplain habitats }\end{array}$ \\
$\begin{array}{c}\text { Create diverse multiage riparian } \\
\text { habitat }\end{array}$ & $\begin{array}{l}\text { cause vertical accretion on floodplain } \\
\text { induce channel migration and thereby create } \\
\text { diverse geomorphic surfaces }\end{array}$ & $\begin{array}{c}\text { produce muddy over-bank flow } \\
\text { erode banks, deposit point bar, over- } \\
\text { bank deposits }\end{array}$ \\
\hline
\end{tabular}

revenue, public safety, and legal constraints. It may still be possible to specify a flushing flow for some objectives such as removing sediments from spawning gravels or prevention of further channel narrowing, whereas other objectives such as maintaining natural channel geometry may no longer be feasible. Sediment entrainment or direct calibration estimates of flushing flows offer the greatest chance of being general and thus applicable to old and new dams because they are typically based on flow and transport calculated from the existing channel. In routine practice, however, such methods may prove no more reliable than others because sediment transport rates are highly sensitive to the magnitude of bed shear stress, which is difficult to estimate accurately in natural channels.

The question of exactly what a "maintenance flow" should "maintain" on an altered river illustrates the need for clearly articulated objectives for flushing flows. Objectives expressed in terms of maintaining "natural" channel conditions clearly cannot be satisfied downstream of a large reservoir, although specific, carefully defined objectives may be achievable.

\section{Specifiable Flushing Objectives}

In order to specify an effective flushing flow, the objectives of that flow must be stated in a manner that permits identification of a particular discharge and water volume to achieve the objectives. In this section we attempt to translate various ecological and management objectives into specifiable flushing flow objectives for which flows can be estimated (Table 1). In some cases the flow necessary to accomplish a specific flushing flow objective may be difficult to determine in advance by any simple method. In all cases there will be uncertainty associated with the estimates of sediment or channel change. Trial releases can be useful in evaluating the accuracy of the transport estimates and the associated flushing flow effectiveness. The important point here is that each objective have associated with it particular physical changes in the stream channel and a definable flow or range of flows that will produce those changes. Then, the costs, constraints, and trade-offs associated with that objective may be addressed, and the compatibility among different objectives may be evaluated.

\section{Restoring/Enhancing Riffle Habitat}

Fine sediments on and within a gravel- and cobble-bed river can degrade the spawning habitat for fish species that lay their eggs on or within the bed and eliminate juvenile rearing habitat in the interstices of the cobbles and gravel [Everest et al., 1987]. Interstitial sediments finer than $1 \mathrm{~mm}$ can decrease the hydraulic conductivity of the gravel, thereby reducing intragravel flow and the supply of oxygenated water to incubating eggs.
Somewhat coarser interstitial sediments (1-9 mm in size) [Tappel and Bjornn, 1983] can fill interstices and physically block emergence of fry from the bed. Aquatic invertebrates also use open interstices in cobbles and gravel; fine sediment deposition can eliminate this habitat.

Restoration and enhancement of riffle habitat will often require removal of fine sediments and, for spawning salmonids, maintaining the "looseness" of gravel deposits. We can define three possible specifiable flushing objectives for riffle habitat: removing fine sediment from the bed surface and from its interstices and maintaining gravel looseness.

Removing surficial fine sediment deposits. It is possible to remove sand from the surface layer of a gravel bed without entraining the gravel [Milhous, 1982; Jackson and Beschta, 1982; Carling, 1984; Kurashige, 1985]. A bed shear stress, $\tau$, that will entrain the sand but not the gravel can be defined on the basis of the grain size of the fine sediment and the median size of the underlying gravel [Milhous and Bradley, 1986]. The most efficient sand removal will occur at $\tau_{0}$ just below that necessary to entrain the gravel. The volume of water required will depend on the quantity of fine sediment in the reach, its transport rate, and the length of the reach [Wilcock et al., 1995].

If surface pore spaces fill with fine sediment, additional sedimentation will result in a relatively homogeneous mantle of fine sediment overlying the sand/gravel substrate. The $\tau_{0}$ required to flush a sand mantle overlying a stable, coarsegrained bed then becomes a function of the sand grain size alone, until the gravel bed is exhumed.

Removing interstitial fine sediment from gravels. To flush fine sediment from deeper than about one coarse grain diameter requires at least some motion of the gravels themselves [Beschta and Jackson, 1979; Diplas and Parker, 1985]. Once gravel clasts are entrained into motion, sand beneath the clasts may be entrained and removed from the bed. The critical shear stress $\tau_{c}$ that produces gravel entrainment may be estimated as a function of the median size of the gravel substrate [Milhous, 1990; Wilcock, 1992]. A critical discharge $Q_{c}$ producing $\tau_{c}$ must then be estimated as a function of channel geometry and roughness. The spatial variability of $\tau_{0}$ in gravel-bed rivers is sufficiently large that section- or reach-average values may not provide reliable estimates of $\tau_{c}$ in much of the channel [Wilcock, 1995]. To accurately specify $Q_{c}$ requires that local values of $\tau_{o}$ be measured or modeled as a function of discharge or that $Q_{c}$ be directly calibrated from entrainment observations during trial releases [Hey, 1981; Wilcock et al., 1995].

Flushing flow prescriptions need to account for other factors, such as the potential for spawning fish to remove fine sediments during construction of their redds [Kondolf et al., 
1993], and the potential for fine sediment intrusion into the bed subsequent to flushing or spawning [Carling and McCahon, 1987], which are functions of the river's sediment load and the timing of sediment transport relative to spawning and incubation. In some cases, flushing flows may not be needed for gravel cleansing beyond what is accomplished by spawning fish. In other cases, flushing flows may need to be timed so the removal of fine sediment is not reversed by subsequent infiltration.

Maintaining gravel looseness. Although the looseness of gravel deposits has been identified as an important attribute of spawning habitat [e.g., Biosystems Analysis, Inc., 1992], no satisfactory method of measuring and quantifying this quality of gravel deposits has been developed. Maintaining a loose texture is likely to require periodic mobilization of gravels similar to that required to remove interstitial fine sediments, so this objective is likely to be satisfied using similar estimates of the critical discharge for gravel entrainment.

\section{Restoring/Enhancing Pool Habitat}

Pool habitat is important for many aquatic organisms, including adult salmon and trout. Deep pools provide cover and, commonly, adequately cool water temperatures to permit salmon and trout to survive warm weather months. Quiet water pool margins are important habitats for juvenile salmon and trout. An influx of fine sediment to the channel, especially if out-of-phase with high river flows, can result in aggradation in pools and loss of this habitat [Lisle and Hilton, 1991]. Scour of sand from pools (and maintenance of pool-and-riffle morphology) can be a specific objective in flushing flows for restoration of aquatic habitat [Wesche, 1991].

The complex flow field in pools and variable geometry from pool to pool make advance estimates of pool scour difficult, although approximate relations may be developed using onedimensional hydraulics and the proportion of sand in the channel and pool [Wilcock et al., 1996]. Wesche [1991] found that a flow equal to 12 times the mean annual flow would flush pools filled with sediment after decades of flow diversions in a set of mountain streams in Wyoming. The scour depth achieved by a particular discharge is likely to increase if a reach becomes gradually flushed of fine sediment, thereby decreasing the fine sediment input to the pools. Monitoring pool fill and scour during flushing releases is likely to be necessary to accurately determine their ongoing effectiveness in scouring pools.

Scour of sand from pools has also been cited as an objective for the Colorado River in the Grand Canyon, although in this case the purpose is to deposit the pool-derived sand on bars used for camping [U.S. Bureau of Reclamation, 1993; Schmidt, 1993].

\section{Maintaining Active Channel Width and Topographic Diversity}

The ecological diversity and productivity of river channels and floodplains is directly related to the areal extent, complexity, and variety of available physical habitats, which include the channel bed, side channels and related habitats, and irregularities in the channel that provide cover and refugia from highvelocity flows (e.g., pool-and-riffle alternations, irregularities in the bank line, and large roughness elements such as tree trunks) [Gregory et al., 1991; Ward and Stanford, 1995]. With reduced flood flows, riparian vegetation can colonize the formerly active channel (with its shallow water table) and induce deposition (within the vegetation) during subsequent high flows [Williams and Wolman, 1984] (Figure 1). This vegetation encroachment and channel narrowing can reduce the hydraulic capacity of the channel (thereby increasing flood hazard), reduce the area of available aquatic habitat, and reduce topographic variability, thereby decreasing the amount and diversity of aquatic habitat [Ligon et al., 1995].

The goal of maintaining active channel width and topographic diversity in rivers with seasonal flow regimes involves, in part, prevention of vegetation encroachment into the active channel. This in turn requires that seedlings of riparian plants be scoured at least biannually to avoid establishment of mature plants with root networks resistant to scour. Relatively little research has been conducted on the shear stresses required to dislodge riparian seedlings [e.g., Oplatka and Sutherland, 1995], but for gravel-bed rivers it is reasonable to specify the flow required to mobilize the bed surface. Young seedlings will not add appreciably to the bed's resistance to scour, nor will they survive mobilization of the surface layer.

The flows needed to scour seedlings from the surface of a gravel bar can be calculated using the same approach one would use to estimate the flows needed to entrain the channel bed, although greater flows may be needed to achieve the necessary depth (and thus $\tau$ ) over the bar. Below new projects, the bank-full discharge may provide a good initial estimate of such a channel maintenance flow because the unvegetated active channel (in which seedlings cannot grow to maturity) corresponds to the area scoured by the bank-full discharge in many rivers. The bank-full discharge may be estimated using a flood with a specified frequency (e.g., the 2-year flood, $Q_{2}$ ) if regional correlations between flood frequency and bank-full discharge are available, or using a flow resistance relation in connection with surveyed channel cross sections. In some cases the bank-full discharge may be sufficiently small that it could be released from large reservoirs without severely affecting project operation.

The frequency of effective channel maintenance flows for natural channels is likely to vary among different hydrologic regions. In channels with ephemeral or highly variable flow, larger, less frequent events are relatively more geomorphically effective [Wolman and Gerson, 1978]. Channel width may depend primarily on the length of time since the last large flood (return period about 10-20 years), since a large flood removes the vegetation and leaves a wide, unvegetated channel of sand and gravel. Following the flood, vegetation colonizes the exposed surfaces and the channel narrows, until the next large flood. Thus a flow comparable to the $Q_{10}$ or greater, and released on the same timescale, might best mimic the channelforming discharge, albeit without the sediment load.

If a channel downstream of a reservoir has narrowed and is flanked by well-established woody vegetation, recovery of the wide, active channel of the predam river would likely require a socially unacceptably large flow, or mechanical removal of vegetated banks along the low-flow channel. Such measures can only be justified when sufficient water is available to prevent channel narrowing from occurring again. A viable alternative may be to create a smaller channel with topographic diversity from features such as migrating bars at the scale of the adjusted channel [Wilcock et al., 1995; Ligon et al., 1995]. On a narrowed channel, gravels can be mobilized at a discharge lower than that required in the predam channel because the reduced width results in an increased depth for a given discharge. 

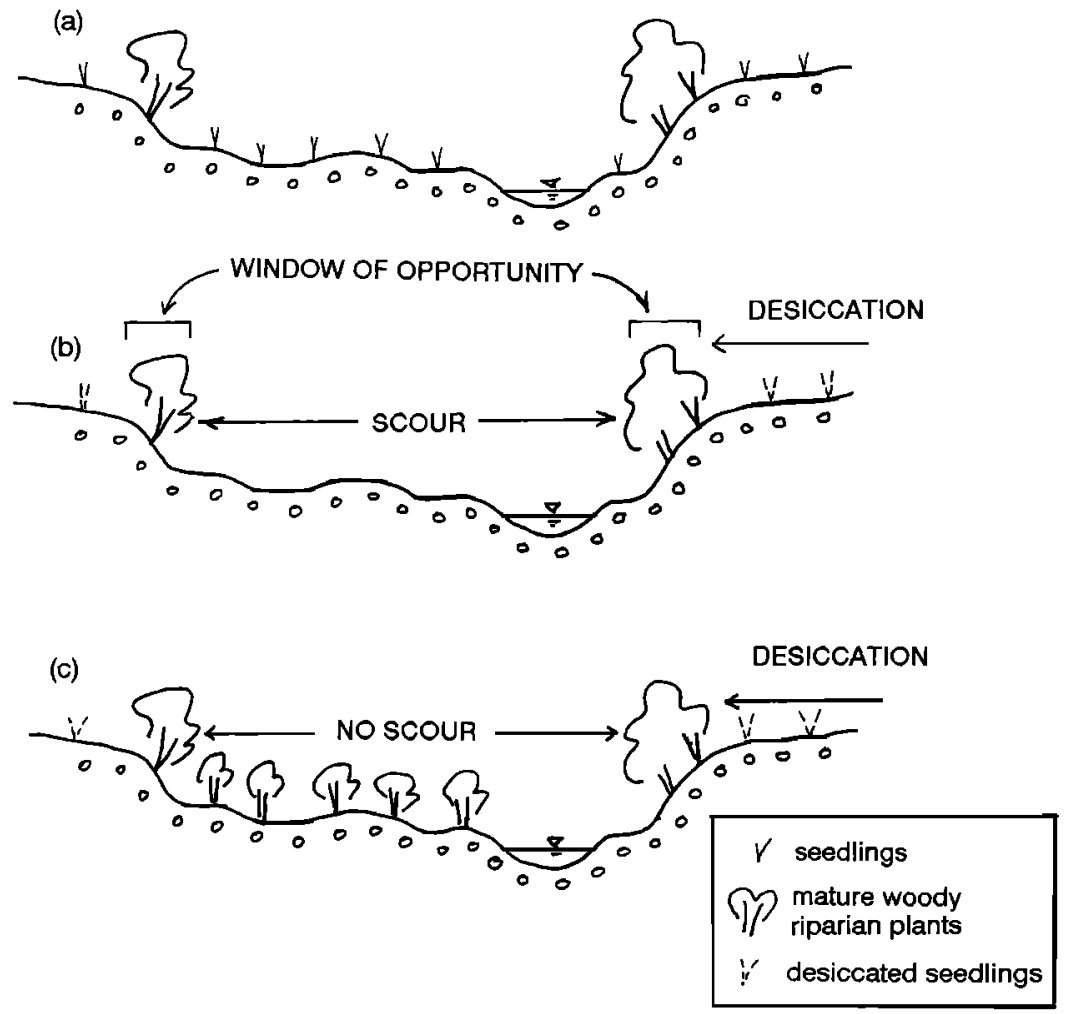

Figure 1. Schematic diagram illustrating (a) seedling distribution following annual flood recession, (b) the "window of opportunity" for establishing riparian vegetation between the zone of scour and zone of desiccation in an unregulated channel, and (c) and encroachment of vegetation into the channel after reducing flood peaks by an upstream reservoir and eliminating scour.

\section{Maintaining Floodplain Habitats}

Floodplain habitats are built largely by vertical accretion of fine sediments deposited from suspended sediment in overbank flows. Flow regulation or channel incision may reduce the frequency of over-bank flooding, which, in combination with reduced suspended sediment loads below the reservoir, may result in reduced over-bank deposition of the sand and silt needed to create and maintain floodplain habitats. Over-bank flows can also provide important spawning and rearing habitat, foraging grounds, and refugia for some fish species [Ligon et al., 1995].

Vertical accretion requires not only a discharge that produces over-bank flooding, but also a sufficient concentration of suspended sediment to permit deposition in the lower-velocity environment of the floodplain. Below large reservoirs that release water with little suspended sediment, suspended sediment must be supplied by downstream tributaries (or other sources such as bank erosion or landslides). Vertical accretion releases should be timed to coincide with high suspended sediment concentrations from tributary inflow or other sources. The discharge necessary may be determined from local stagedischarge relations, or from standard backwater modeling of adjusted channels.

Hill et al. [1991, p. 199] suggested that preservation of overbank flows and "flood flows that form floodplain and valley features" could be achicved by release of approximately the $Q_{25}$; they did not explicitly address sediment supply below reservoirs.
On Rush Creek in Mono Basin, California, historical dewatering of the stream and lowering of base level resulted in extensive channel widening. Goals of ecological restoration there included recreation of a narrow channel by building new floodplains on the over-widened active channel bed, so objectives for channel maintenance flushing flows included overbank flooding and deposition. Flushing flow releases comparable to the $Q_{2}$ of the flow regime existing prior to dewatering have been specified to encourage floodplain building [State of California Water Resources Control Board (SWRCB), 1994].

\section{Creating Diverse MultiAge Riparian Habitat}

The diversity of riparian habitat depends upon the diversity of physical environments for vegetation, ranging from freshly deposited, coarse-grained point bars (colonized by early successional species) to higher floodplain surfaces underlain by fine-grained over-bank sediments (supporting mature, later successional species). The diversity of this physical habitat is maintained by active channel migration [Ward and Stanford, 1995]. Reduced floods and sediment supply below dams may cause channel degradation and reduced rates of channel migration, thereby eliminating the erosion of meander bends and creation of new point bar habitat. As a result, the areal extent of pioneer forests may decline, offset by an increase in extent of later successional species, and resulting in an overall loss of species (and therefore habitat) diversity [Johnson, 1992].

Diverse, multiage stands of riparian vegetation require dynamic channel migration. To maintain meander migration 
Table 2. Flushing Flow Constraints

\begin{tabular}{|c|c|}
\hline $\begin{array}{c}\text { Ecological or Management } \\
\text { Constraints }\end{array}$ & Specific Constraint \\
\hline $\begin{array}{l}\text { Preserve spawning gravel in } \\
\text { reach }\end{array}$ & $\begin{array}{l}\text { Minimize gravel transport, subject } \\
\text { to sufficient entrainment for } \\
\text { gravel maintenance }\end{array}$ \\
\hline Preserve active redds & $\begin{array}{l}\text { Avoid scour of embryos by timing } \\
\text { flushing flow to avoid } \\
\text { incubation period }\end{array}$ \\
\hline $\begin{array}{l}\text { Minimize cost of water and } \\
\text { loss of hydroelectric } \\
\text { generation }\end{array}$ & $\begin{array}{l}\text { Minimize volume of water used in } \\
\text { flushing flow release }\end{array}$ \\
\hline Control floods & $\begin{array}{l}\text { Limit discharge to avoid } \\
\text { inundation of structures on } \\
\text { floodway or formerly active } \\
\text { channel }\end{array}$ \\
\hline Protect structures & $\begin{array}{l}\text { Limit discharge, duration, and } \\
\text { rate of stage change to avoid } \\
\text { bank erosion where structures } \\
\text { are present }\end{array}$ \\
\hline
\end{tabular}

rates, flushing flow releases must be high enough to induce bank erosion. The flows needed for this purpose may be estimated from historical channel migration rates associated with different discharges. Bank erosion could also be enhanced by abrupt declines in river stage following a prolonged high stage, which may induce sloughing of chunks of fine-grained bank by development of positive pore pressures from the bank to the channel. Meander cutoffs (and the active erosion and deposition associated with them) could be encouraged by notching the banks at potential cutoff locations [Ligon et al., 1995].

\section{Constraints}

Flushing flow objectives must typically be considered in the context of one or more ecological or management constraints, which are listed (with their specific influence on flushing flow releases) in Table 2.

\section{Preserving Spawning Gravels}

If gravel transport during flushing flows exceeds supply from upstream (as may typically occur downstream of a reservoir), the extent of spawning gravels may decline. To minimize gravel loss, gravel transport rates must be minimized. Because some flushing flow objectives require mobilization of the gravel bed, this constraint can directly conflict with the flow objectives. An important alternative in such cases is artificial replacement of gravel or inducement of local bank erosion when banks contain suitably sized gravels.

\section{Preserving Active Redds}

Incubating embryos are vulnerable to destruction if their redds are scoured during high flows. To avoid scour of embryos requires that spawning gravels are not scoured to the depth of the egg pockets while eggs (or hatched alevins) are present in the gravel. This requires either that flushing be timed to avoid incubation periods (which vary with species and water temperature but are typically 6-10 weeks in the winter or spring), or that scour be shallower than the egg pockets (whose depths vary with species, but typically range from 10 to $30 \mathrm{~cm}$ [Everest et al., 1987]). The same set of analytical approaches used to specify flushing flows for mobilization of the gravel bed for sediment maintenance can be used to predict scour depth and thus specify the flow levels associated with this constraint.

\section{Minimizing Cost of Water and Loss} of Hydroelectric Revenue

The potential benefits of flushing flows must be weighed against the cost of the releases in terms of lost water (for municipal or agricultural use) and lost hydroelectric generation. The optimal flushing flow is one that achieves its flushing objective with a minimum cost. A benefit of carefully defined flushing flow objectives is evident here. Different combinations of discharge, water volume, and nonflow alternatives may be found that satisfy the objective, whereas one particular combination is likely to have minimum cost.

The cost of flushing flows depends not only on the amount of water consumed in the release, but also the timing of the release and whether some of the release can be used to generate power (a function of the dam and power plant configuration and type of project). For example, if the release is made during the wet seasons, there is a greater likelihood that the water released from a small reservoir may be replaced by new water flowing in from upstream than if the release is made during the dry season when reservoir inflow is low. In a reservoir with a large storage capacity relative to runoff, the seasonal timing may be less important because of carry-over storage from year to year.

\section{Flood Control}

After reservoir construction, land-planning authorities may rezone former floodplain areas as no longer flood-prone and therefore suitable for settlement. Downstream of large reservoirs the postdam 100-year flood may be a small fraction of the predam flood, and the 100-year inundation area so reduced that structures are permitted to be built on the banks of the narrowed, postdam channel [Wilcock et al., 1995]. Thus legal flood control requirements (and the political repercussions of flooding structures) may severely constrain the flushing flow magnitude.

\section{Preventing Bank Erosion}

The encroachment of human settlement onto the formerly active channel (discussed above) can create another constraint upon flushing flow magnitude and duration. Loss of structures or land to bank erosion can be expected to stimulate complaints or legal actions from the affected landowners. This constraint directly conflicts with the objective of maintaining diverse multiage riparian habitat and gravel supply from bank erosion.

\section{Compatibility of Flushing Flow Requirements}

Review of the existing literature on flushing flows [Reiser et al. 1985] suggests that the distinction between specific flushing objectives has not always been explicitly recognized, and many practitioners have evidently assumed that a single flow can be specified to perform all the desired functions on a given river. However, there is no a priori basis for assuming that a single flow will perform all the functions of the range of floods under the natural, predam hydrologic regime, especially given that dams alter both sediment and flow regimes. Having stated flushing flow objectives in terms of specific physical processes, it becomes possible to evaluate whether these objectives are compatible. 


\section{Narrow Window for Flushing Fine Sediments from Gravel}

The objectives of entraining gravel to permit subsurface flushing and loosening of the bed structure may conflict with the constraint of preserving channel gravels. To minimize the cost of water used for flushing flows, it is desirable to maximize the rate at which sand is removed. Because the efficiency of sand transport $Q_{s}$ increases with discharge $Q\left(Q_{s} \propto Q^{b}\right.$, where $b>1$ ), the largest possible discharge will maximize sand removal efficiency. At the same time, however, higher flows produce a larger gravel transport rate. If the gravel transport rate approaches that of the sand (when each is scaled by the proportions of gravel and sand in the bed), the selective transport needed for net reduction in sand content is eliminated, and the future composition of the bed will be determined by a balance between upstream sediment supply and transport from the reach. In some cases this will result in a fining of the bed. If gravel transport during flushing flows exceeds gravel supply, the gravel content in the reach will be reduced.

Clearly, no flushing flow can both maximize sand removal and minimize gravel transport. The best solution is a flow that produces sufficient gravel entrainment to expose the bed subsurface and loosen the bed structure while also producing a sand-to-gravel transport ratio sufficiently large to permit net sand removal. Field and laboratory transport observations suggest that these transport conditions exist over a narrow range of discharge [Wilcock, 1995], as illustrated in Figure 2, for the Trinity River in northern California [Wilcock et al., 1995] and for a laboratory sediment [Wilcock and McArdell, 1993]. Shown for each case is a scour threshold $\tau_{s c}$ representing mean bed scour to a depth of approximately $D_{90}$ [Wilcock, 1995]. The transport rates $q_{b i}$ of the sand and gravel are scaled by the proportion $f_{\iota}$ of each in the bed. Both cases show that sand is preferentially transported at smaller $\tau_{0}$. The onset of general gravel entrainment does not occur, however, until the gravel transport rates approach those of the sand. In the laboratory case, $\tau_{s c}$ is not associated with uniform scour: less than $25 \%$ of the coarsest grains (greater than $D_{90}$ ) are entrained. At the largest transport observed with the laboratory sediment $\left(\tau_{0} \approx\right.$ $1.3 \tau_{s c}$ ), nearly all of the gravel clasts on the bed surface are entrained, but the gravel transport rate is within $20 \%$ of that of the sand [Wilcock, 1995]. In the field case, $\tau_{o}$ for equivalent sand and gravel transport rates is only 10-20\% larger than $\tau_{s c}$, a result that may be typical because in many gravel bed rivers, $\tau_{o}$ rarely exceeds the critical shear stress for incipient motion of the gravel by more than $20 \%$ [Parker, 1979].

In both cases in Figure 2, selective sand transport does occur in the presence of entrainment of most of the bed surface, but over only a small range of $\tau_{0}$. A critical trade-off exists between the proportion of gravel in transport (which determines the degree of selective sand transport) and the proportion of gravel on the bed surface that is entrained (allowing subsurface flushing and bed loosening). A superior solution may involve artificial gravel replenishment and pool dredging to increase the rate of sand removal and reduce gravel loss. Specification of an effective flushing flow requires a quantitative analysis of the trade-off among all these alternatives, which must be based on estimates of sand and gravel transport as a function of flushing discharge and water volume [Wilcock et al., 1996]. The identification of a narrow range of relatively small discharges producing effective sediment maintenance flushing introduces important

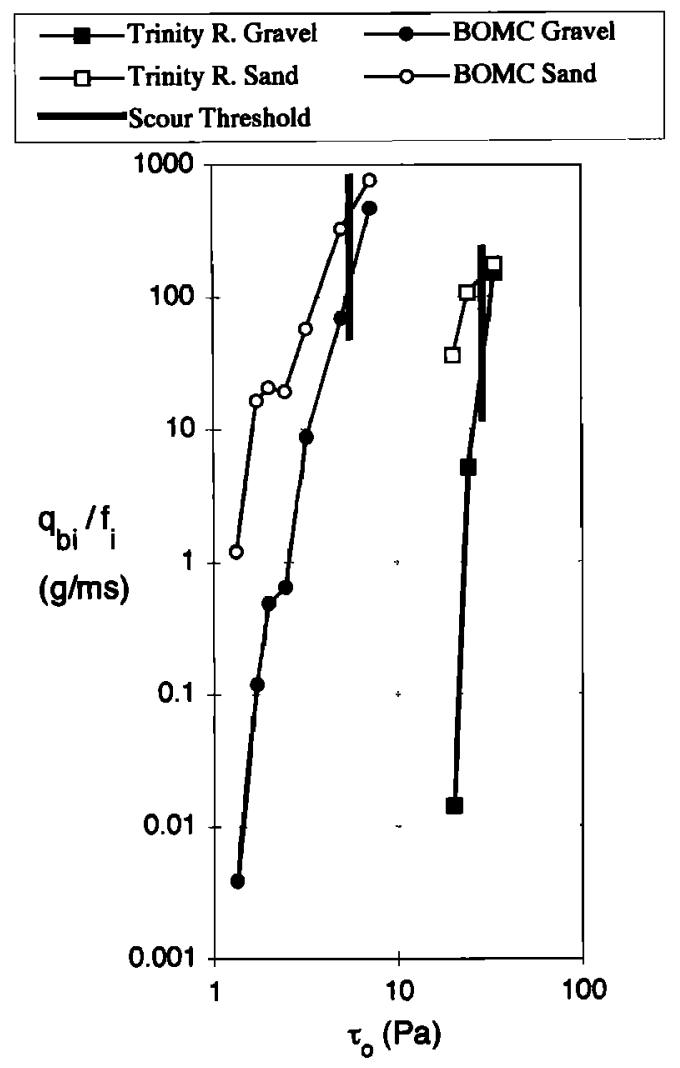

Figure 2. Sand and gravel transport rates as a function of bed shear stress for Trinity River at Poker Bar [Wilcock et al., 1995] and the bed of many colors (BOMC) laboratory sediment of Wilcock and McArdell [1993]. Transport rates of sand and gravel are scaled by the proportion $f_{i}$ of each fraction present in the bed. Bed shear stress $\tau_{o}$ is an estimate of local values over width of sampled transport. Scour threshold $\tau_{\text {sc }}$ is the value of $\tau_{o}$ producing mean bed scour to a depth of $D_{90}$. In each case, flows with $\tau_{o}>\tau_{\text {sc }}$ produce gravel transport at a rate close to that of the sand, minimizing selective sand transport.

conflicts with other flushing objectives, many of which require a large discharge.

\section{Conflict Between Preventing Vegetation Encroachment and Preventing Gravel Loss}

Flows requiring gravel entrainment throughout a river cross section to remove vegetation seedlings from the active channel or maintain active transport on bars are likely to be larger than flows that produce selective transport and effective sediment maintenance along the channel bottom. An illustration of this potential conflict may be made for a typical case in which flows are to mobilize the bed surface on the top of a bar in a sand-gravel-cobble stream. An approximate analysis of the degree of gravel transport on the channel bottom can be made by assuming the local shear stress is everywhere proportional to the local flow depth. The shear stress on the channel bed and on the bar top may then be written as

$$
\begin{gathered}
\tau_{\mathrm{ch}}=\rho g h_{\mathrm{ch}} S, \\
\tau_{\mathrm{br}}=\rho g h_{\mathrm{bT}} S
\end{gathered}
$$


where $\rho$ is water density, $g$ is acceleration of gravity, $h$ is flow depth, $S$ is water surface slope, and the subscripts "ch" and "br" refer to the channel and bar top, respectively. The critical shear stress at each location can be estimated as

$$
\begin{gathered}
\tau_{c \mathrm{ch}}=\tau_{c}^{*}\left(\rho_{s}-\rho\right) g D_{\mathrm{cb}}, \\
\tau_{c \mathrm{br}}=\tau_{c}^{*}\left(\rho_{s}-\rho\right) g D_{\mathrm{br}}
\end{gathered}
$$

where $\tau_{c}^{*}$ is the dimensionless critical shear stress which may be assumed to take a value on the order of 0.03 to 0.04 for the purpose of this exercise. The degree to which the shear stress in the channel exceeds the critical shear stress may be obtained from (1a) and (2a) as

$$
\frac{\tau_{\mathrm{ch}}}{\tau_{\mathrm{cch}}}=\frac{h_{\mathrm{ch}} S}{\tau_{c}^{*}\left(\rho_{s} / \rho-1\right) D_{\mathrm{ch}}}
$$

Expressing $h_{\mathrm{ch}}$ as the sum of $h_{\mathrm{br}}$ and bar height $\delta$, (3) may be rewritten as

$$
\frac{\tau_{\mathrm{ch}}}{\tau_{c \mathrm{ch}}}=\frac{h_{\mathrm{br}} S}{\tau_{c}^{*}\left(\rho_{s} / \rho-1\right) D_{\mathrm{ch}}}+\frac{\delta S}{\tau_{c}^{*}\left(\rho_{s} / \rho-1\right) D_{\mathrm{ch}}}
$$

Using (1a) and (1b) to replace $h_{\mathrm{br}} S$ and using (2b) to replace $\tau_{c}^{*}$, the first term on the right side of (4) may be expressed as $\left(\tau_{\mathrm{br}} / \tau_{\mathrm{cbr}}\right)\left(D_{\mathrm{br}} / D_{\mathrm{ch}}\right)$. Using this expression and defining a dimensionless bar height $\Delta=\delta / D_{\mathrm{ch}}$, (4) may be reduced as

$$
\frac{\tau_{\mathrm{ch}}}{\tau_{c \mathrm{ch}}}=\frac{\tau_{\mathrm{br}}}{\tau_{\mathrm{cbr}}} \frac{D_{\mathrm{br}}}{D_{\mathrm{ch}}}+\Delta \frac{S}{\tau_{c}^{*}\left(\rho_{s} / \rho-1\right)}
$$

Assuming $\tau_{\mathrm{br}} / \tau_{c \mathrm{br}}=1$ to represent the case where flow over the bar top is just sufficient to entrain the sediment there, (6) shows that $\tau_{\mathrm{ch}} / \tau_{c \mathrm{ch}}$ depends primarily on the grain-size ratio $D_{\mathrm{br}} / D_{\mathrm{ch}}$, dimensionless bar height $\Delta$, and water surface slope $S$. Using (5) and assuming $\tau_{c}^{*}=0.035$ and $\rho_{s} / \rho=2.65$, Figure 3 presents values of $\tau_{\mathrm{ch}} / \tau_{c \mathrm{ch}}$ as a function of $D_{\mathrm{br}} / D_{\mathrm{ch}}$ for different values of $\Delta$ and $S=0.001,0.0035$, and 0.01 . A continuous scale is used for $D_{\mathrm{br}} / D_{\mathrm{ch}}$, because a wide variation in this variable is possible. (Mosley and Tinsdale [1985] found no correlation between grain size and bed elevation in transacts across a braided stream cross section.)

Figure 3 suggests that if the bar top sediment is coarser than the channel $\left(D_{\mathrm{br}} / D_{\mathrm{ch}}>1.0\right)$, values of $\tau_{\mathrm{ch}} / \tau_{c \mathrm{ch}}$ will always be large, regardless of $\Delta$ and $S$. It is not possible to scour bar tops without producing fully mobilized transport in the channel (which may lead to unacceptable gravel loss) if the grain size of the bar top is much greater than that of the channel. If $D_{\mathrm{br}} / D_{\mathrm{ch}}<$ 1.0 , the value of $\tau_{\mathrm{ch}} / \tau_{c \mathrm{ch}}$ depends strongly on the stream slope. For steep streams, for which the proportional increase in $\tau$ for a change in $h$ is greater, bar top scour without high mobility in the channel cannot be achieved except for bar heights only slightly larger than the channel grain size. For lower gradient streams it is possible to scour the bar top without large gravel transport in the channel for a range of bar heights.

The approximations used to develop (5) make Figure 3 more illustrative than predictive. Only a single representative grain size is included for each of the bar and channel. Use of the median grain size $D_{50}$ would provide a reasonable approximation of $\tau_{c}$ for the bed in unimodal, but not strongly bimodal sediment mixtures [Wilcock, 1993]. In bimodal sediments, $\tau_{c}$ for the coarse fraction will be greater than that for $D_{50}$, which would provide a favorable reduction in $\tau_{\mathrm{ch}} / \tau_{c \mathrm{ch}}$ for bimodal channel sediment, but would reduce $\tau_{\mathrm{ch}} / \tau_{c \mathrm{ch}}$ for the case of bimodal sediment on the bar top. The assumption that the local shear stress is directly proportional to the local flow depth is clearly violated in regions of rapidly varying flow, particularly at the upstream and downstream ends of a bar [Whiting and Dietrich, 1991]. Nonetheless, the general trends shown in Figure 3 are unlikely to be significantly different if a more complete flow model were used, because the effect of convective accelerations will be to both increase and decrease local shear stress, depending on location, and because the contribution of convective acceleration to local shear stress is likely to be much smaller than the local depth-slope product over much of the bar surface.

More detailed calculations of the local flow and transport field are not likely to change the general conclusions that may be drawn from Figure 3. Bar scour without significant gravel loss in the channel is unlikely if the bar top grain size is larger than that in the channel. When the bar top is finer than the channel, the range of flushing flows that might produce both sediment and channel maintenance depends strongly on slope: it becomes vanishingly small at high slopes; at low slopes there may be some opportunity to define a dual-purpose flushing flow.

Flushing flows producing entrainment throughout the river cross section may be desirable and specified for the purpose of vegetation removal or bar migration, even though they produce a large amount of gravel loss. In cases with limited upstream gravel supply, such large flushing flows must be accompanied by sufficient gravel supply either through local bank erosion, tributary contribution, or an artificial supply. The selection of such an alternative (and the specification of particular discharge and gravel replenishment values) will require quantitative estimates of gravel loss, so that the cost of gravel replacement can be assessed relative to other alternatives, such as mechanical removal of vegetation.

\section{Conflict Between Floodplain Building and Maintaining In-Channel Topographic Diversity}

As floodplain deposits, especially the natural levee deposits adjacent to the low flow channel, aggrade, flows may be increasingly confined within the low flow channel, resulting in greater depth and velocity within the low flow channel for a given discharge. This flow confinement reduces in-channel topographic diversity, thereby reducing the quality of aquatic habitat. When vegetation encroachment promotes deposition of fine-grained sediment and bank building within the formerly active channel, aquatic habitat area and diversity can be substantially reduced. Mechanical removal of such banks may be used in conjunction with future flushing flows to prevent reencroachment. Rapid deposition of such banks may be prevented by timing flushing flow releases so they do not coincide with tributary floods with high suspended sediment concentrations.

\section{Conflict Between Flushing Flow Objectives and Flood Control/Bank Erosion Constraints}

In addition to conflicts among objectives, the constraints on flushing flows will typically also require trade-offs between benefits and costs. Vertical accretion flows require muddy over-bank flows, but human settlements along the banks and on the bed of the formerly active channel may be flooded by these over-bank flows. Unless the settlements are limited, purchased by the government, or the landowners compensated for flood losses, their presence on the former active channel will typically mean vertical accretion flows are either not possible 


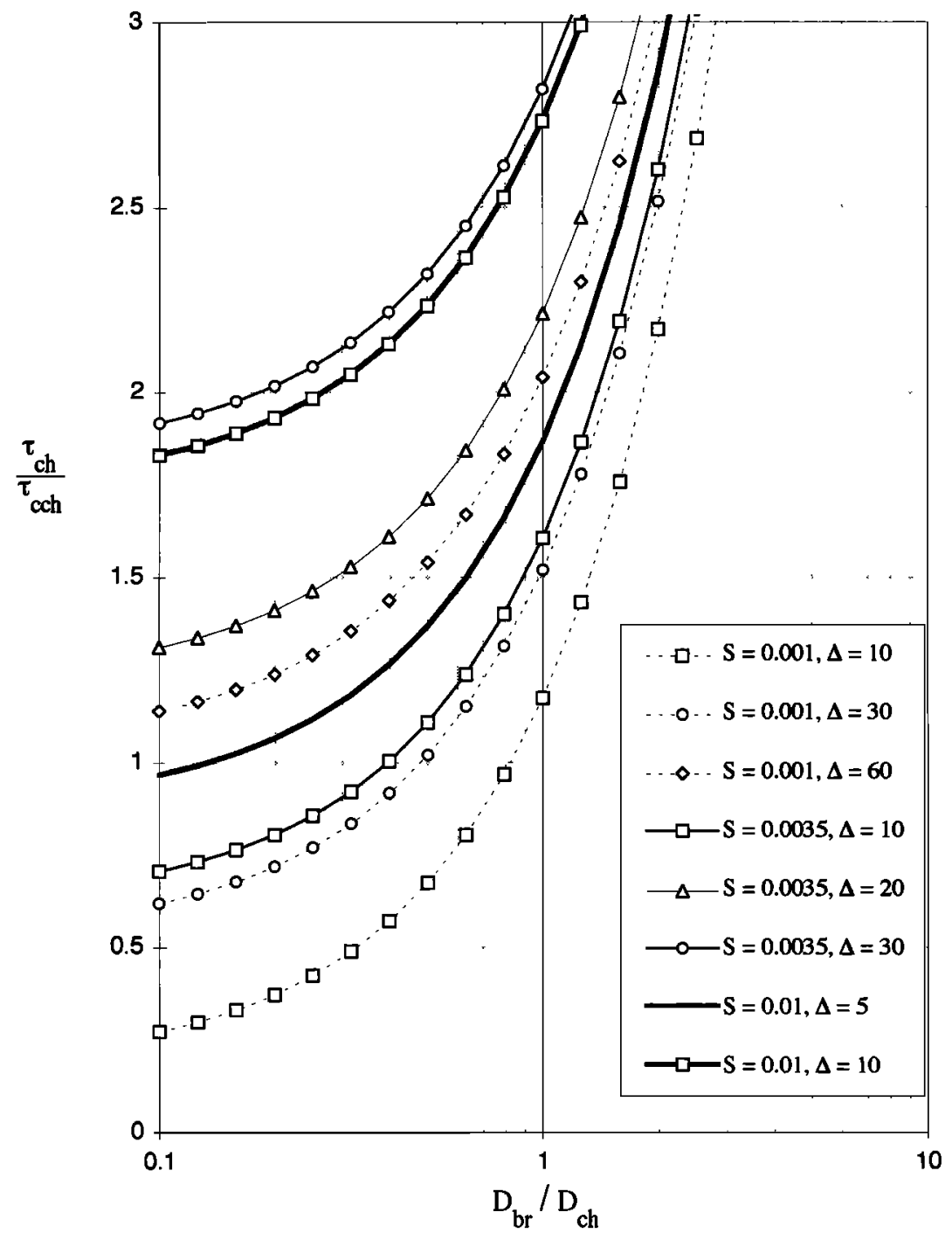

Figure 3. Ratio of shear stress to critical shear stress $\left(\tau_{c h} / \tau_{c c h}\right)$ in channel for flows producing entrainment of sediment on the top of an adjacent bar plotted as a function of the ratio of grain size for the bar and channel $\left(D_{\mathrm{br}} / D_{\mathrm{ch}}\right)$ for channel slope $S=0.001,0.0035,0.01$ and various values of dimensionless bar height $\Delta ; \tau_{\mathrm{ch}} / \tau_{c \mathrm{ch}}$ increases directly with all of $D_{\mathrm{br}} / D_{\mathrm{ch}}, S$, and $\Delta$ and generally takes values that would not permit selective sand transport in the channel.

or must be limited to surfaces below the elevation of the settlements.

Channel migration requires bank erosion (accompanied by point bar deposition), while bank erosion must be arrested to protect structures built along the channel (or other land uses located there) and threatened by bank erosion. As with the conflict between vertical accretion flows and flood control, protection of the structures will typically have priority.

To permit over-bank and bank-eroding flows (and their attendant ecological benefits) may require that structures be prohibited from the meander belt and that other land uses (such as recreation or agriculture) be permitted only to the extent that it is understood that they do not warrant bank protection.

\section{Summary and Conclusions}

A wide range of ecological or management objectives have been cited for flushing flows, ranging from maintaining gravel quality to maintaining active channel width and habitat diversity. Often, the objectives stated are too broad to permit specification of a particular discharge and water volume. Also, flushing flows may be specified in terms of a particular method without sufficient consideration of the benefits that are to be produced by the flow. Flushing objectives that do not permit specification of a particular flow are of little practical use, regardless of their intrinsic merit.

To determine an appropriate and effective flushing flow release requires that the ecological and management objectives be translated into specific, achievable physical objectives. These include flows to mobilize the surface layer of the channel bed, remove sand from pools, erode channel banks, and deposit sediment on floodplains. These physical processes (which support the ecological resources of interest) may be estimated in advance and verified by observations during initial releases.

Once clearly specified, flushing flow objectives can be eval- 
uated to identify potential incompatibilities. Sand removal efficiency increases with discharge, but so does the rate of gravel loss. Sand removal from the subsurface requires gravel transport at a rate approaching that of the sand, so that effective sand removal is restricted to only a narrow window of discharge. Active transport throughout the channel to prevent vegetation encroachment may produce excessive gravel loss through deeper parts of the channel. Over-bank flooding to support floodplain habitat can cause bank deposition that diminishes topographic diversity for within-channel flows. Conflicts also arise between flushing flow objectives and management constraints to minimize water costs and protect structures from flooding and bank erosion.

The potential incompatibility among flushing flow objectives points toward the need for explicit calculations of sand and gravel transport under different flushing flow alternatives. Selection of an effective flushing flow rate and volume, along with other alternatives such as gravel replenishment, mechanical bank manipulation, and pool dredging, requires estimating sand and gravel supply and transport rate through the river channel. Only by determining these quantities will it be possible to evaluate the impacts and costs of the different alternatives in specifying an effective flushing flow.

Acknowledgments. The authors have benefited from illuminating discussions on these subjects with Alan Barta, Andy Hamilton, Tom Lambert, Tom Lisle, Graham Matthews, Robert Milhous, John Pitlick, Conor Shea, and Bill Trush. Many of the concepts presented here were developed in the course of a 3-year study of flushing flow requirements on the Trinity River, California, funded by the U.S. Fish and Wildlife Service and administered by the Center for Environmental Design Research at the University of California and the Department of Geography and Environmental Engineering at the Johns Hopkins University. Manuscript preparation was supported by an award for Research Excellence in Wildlands from Pacific Gas and Electric Company, administered by the University of California Water and Wildland Resources Center, Davis.

\section{References}

Beschta, R. L., and W. L. Jackson, The intrusion of fine sediments into a stable gravel bed, J. Fish. Res. Board Can., 36, 204-210, 1979.

Biosystems Analysis, Inc., Lower Mokelumne River management plan, San Francisco, Calif., 1992

Carling, P. A., Deposition of fine and coarse sand in an open work gravel bed, Can. J. Fish. Aquat. Sci., 41, 263-270, 1984.

Carling, P. A., and C. P. McCahon, Natural siltation of brown trout (Salmo trutta $L$.) spawning gravels during low-flow conditions, in Regulated Streams: Advances in Ecology, edited by J. F. Craig and J. B. Kemper, pp. 229-244, Plenum, New York, 1987.

Diplas, P., and G. Parker, Pollution of gravel spawning grounds due to fine sediment, St. Anthony Falls Hydrol. Lab. Proj. Rep. 240, Univ. of Minn., Minneapolis, 1985.

Everest, F. L., R. L. Beschta, J. C. Scrivener, K. V. Koski, J. R. Sedell, and C. J. Cederholm, Fine sediment and salmonid production-a paradox, in Streamside Management: Forestry and Fishery Interactions, edited by E. O. Salo and T. W. Cundy, pp. 98-142, Coll. of Nat. Resour., Univ. of Wash., Seattle, 1987.

Gregory, S. V., F. J. Swanson, W. A. McKee, and K. W. Cummins, An ecosystem perspective of riparian zones, Bioscience, 41, 540-551, 1991.

Hesse, L. W., and W. Sheets, The Missouri River hydrosystem, Fisheries, 18(5), 5-14, 1993.

Hey, R. D., Channel adjustment to river regulation schemes, in Proceedings of Workshop on Downstream River Channel Changes Resulting from Diversion or Reservoir Construction, Rep. FWS/OBS-81/48, U.S. Fish and Wildlife Serv., pp. 114-127, Fort Collins, Colo., 1981.

Hill, M. T., W. S. Platts, and R. L. Beschta, Ecological and geomorphological concepts for instream and out-of-channel flow requirements, Rivers, 2, 198-210, 1991.
Hoppe, T. M., and R. A. Finnell, Aquatic studies on the Fryingpan River, Colorado-1969-1970, US Bureau of Sport Fish, Denver, Colorado, unpublished report, 1970. (as cited by eiser et al. 1989)

Jackson, W. L., and R. L. Beschta, A model of two-phase bedload transport in an Oregon Coast Range stream, Earth Surf. Processes Landforms, 7, 517-527, 1982.

Johnson, W. C., Dams and riparian forests: Case study from the upper Missouri River, Rivers, 3, 229-242, 1992.

Kondolf, G. M., G. F. Cada, and M. J. Sale, Assessing flushing-flow requirements for brown trout spawning gravels in steep streams, Water Resour. Bull., 23, 927-935, 1987.

Kondolf, G. M., M. J. Sale, and M. G. Wolman, Modification of gravel size by spawning salmonids, Water Resour. Res., 29, 2265-2274, 1993.

Kurashige, Y., Model for pulling up fine particles from armour-coated gravel bed in the early snowmelt season, Trans. Jpn. Geomorph. Union, 6, 287-302, 1985.

Lamb, B. L., and H. R. Doerksen, Instream water use in the United States-Water laws and methods for determining flow requirements, U.S. Geol. Surv. Water Supply Pap. 2350, 109-116, 1987.

Ligon, F. K., W. E. Dietrich, and W. J. Trush, Downstream ecological effects of dams, a geomorphic perspective, Bioscience, 45(3), 183192, 1995.

Lisle, T. E., and S. Hilton, Fine sediment in pools: An index of how sediment is affecting a stream channel, USDA Forest Service Pacific southwest Region, R-5 Fish Habitat Relat. Tech. Bull., 6, 1991.

Loar, J. M., and M. J. Sale, Analysis of environmental issues related to small scale hydroelectric development, V, Instream flow needs for fishery resources, Rep. ORNL/TM-7861, Environ. Sci. Div., Oak Ridge Natl. Lab., Oak Ridge, Tenn., 1984.

Milhous, R. T., Effect of sediment transport and flow regulation on the ecology of gravel bed rivers, in Gravel Bed Rivers, edited by R. D. Hey, J. C. Bathurst, and C. R. Thorne, pp. 819-841, John Wiley, New York, 1982.

Milhous, R. T., Calculation of flushing flows for gravel and cobble bed rivers, in Hydraulic Engineering, vol. 1, Proceedings of the $1990 \mathrm{Na}$ tional Conference, edited by H. H. Chang and J. C. Hill, pp. 598-603, Am. Soc. of Civ. Eng., New York, 1990.

Milhous, R. T., and J. B. Bradley, Physical habitat simulation and the moveable bed, in Water Forum '86: World Water Issues in Evolution, vol. 2, pp. 1976-1983, Am. Soc. Civ. Eng., New York, 1986.

Montana Department of Fish, Wildlife, and Parks, Instream flow evaluation for selected waterways in western Montana, report to U.S. For. Serv., Missoula, Mont., 1981.

Mosley, M. P., and D. S. Tinsdale, Sediment variability and bed material sampling in gravel bed rivers, Earth Surf. Processes Landforms, 10, 465-482, 1985.

O'Brien, J. S., A case study of minimum streamflow for fishery habitat in the Yampa River, in Sediment Transport in Gravel-Bed Rivers, edited by C. R. Thorne, J. C. Bathurst, and R. D. Hey, pp. 921-946, John Wiley, New York, 1987.

Oplatka, M., and A. Sutherland, Tests on willow poles used for river bank protection, J. Hydrol. N. Z., 33(1), 35-58, 1995.

Parker, G., Hydraulic geometry of active gravel rivers, J. Hydraul. Div. Am. Soc. Civ. Eng., 105(HY9), 1185-1201, 1979.

Reiser, D. W., M. P. Ramey, and T. R. Lambert, Review of flushing flow requirements in regulated streams, Bechtel Group, San Francisco, Calif., 1985.

Reiser, D. W., M. P. Ramey, and T. A. Wesche, Flushing flows, in Alternatives in Regulated River Management, Chap. 4, edited by J. A. Gore and G. E. Petts, pp. 91-135, CRC Press, Boca Raton, Fla., 1989.

Resh, V. H., A. V. Brown, A. P. Covich, M. E. Gurtz, H. W. Li, G. W. Minshall, S. R. Reice, A. L. Sheldon, J. B. Wallace, and R. C. Wissmar, The role of disturbance in stream ecology, J. N. Am. Benthological Soc., 7, 433-455, 1988.

Schmidt, J. C., D. M. Rubin, and H. Ikeda, Flume simulation of recirculating flow and sedimentation, Water Resour. Res., 29(8), 2925-2939, 1993.

Sparks, R. E., P. B. Bayley, S. L. Kohler, and L. L. Osborne, Disturbance and recovery of large floodplain rivers, Environ. Manage., 14, $699-709,1990$.

State of California Water Resources Control Board (SWRCB), Mono Lake Basin Water Right Decis. 1631, Sacramento, 1994.

Tappel, P. D., and P. C. Bjornn, A new method of relating size of spawning gravel to salmonid embryo survival, N. Am. J. Fish. Manage., 3, 123-135, 1983. 
Tennant, D. L., Instream flow regimens for fish, wildlife, recreation and related environmental resources, in Proceedings of Symposium and Specialty Conference on Instream Flow Needs, vol. 2, pp. 359373, Am. Fish. Soc., Bethesda, Md., 1976.

U.S. Bureau of Reclamation, Operation of Glen Canyon Dam, Colorado River Storage project, Arizona, Draft Environmental Impact Statement, Salt Lake City, Utah, 1993.

Ward, J. V., and J. A. Stanford, Ecological connectivity in alluvial river ecosystems and its disruption by flow regulation, Regul. Rivers Res. Manage., 11, 105-119, 1995.

Wesche, T. A., Flushing flow requirements of mountain stream channels, Ph.D. dissertation, Wash. State Univ., Pullman, 1991.

Whiting, P. J., and W. E. Dietrich, Convective accelerations and boundary shear stress over a channel bar, Water Resour. Res., 27(5), 783-796, 1991.

Wilcock, P. R., Flow competence: A criticism of a classic concept, Earth Surf. Processes Landforms, 12, 289-298, 1992.

Wilcock, P. R., Critical shear stress of natural sediments, J. Hydraul. Eng., 119, 491-505, 1993.

Wilcock, P. R., Sediment maintenance flows: Feasibility and basis for prescription, paper presented at Gravel-Bed Rivers Workshop IV, Oreg. Water Resour. Res. Inst., Gold Bar, Wash., Aug. 1995.

Wilcock, P. R., and B. W. McArdell, Surface-based fractional transport rates: Mobilization thresholds and partial transport of a sand-gravel sediment, Water Resour. Res., 29, 1297-1312, 1993.
Wilcock, P. R., G. M. Kondolf, A. F. Barta, W. V. G. Matthews, C. C. Shea, Spawning gravel flushing during trial reservoir releases on the Trinity River: Field observations and recommendations for sediment maintenance flushing flows, Rep. 05-95, 222 pp., Cent. for Environ. Design Res., Univ. of Calif., Berkeley, 1995.

Wilcock, P. V., G. M. Kondolf, W. V. G. Matthews, and A. F. Barta, Specification of sediment maintenance flows for a large gravel-bed river, Water Resour. Res., in press, 1996.

Williams, G. P., and M. G. Wolman, Downstream effects of dams on alluvial rivers, U.S. Geol. Surv. Prof. Pap. 1286, 1984.

Wolman, M. G., and R. Gerson, Relative scales of time and effectiveness of climate in watershed geomorphology, Earth Surf. Processes Landforms, 3, 189-208, 1978.

G. M. Kondolf, Department of Landscape Architecture, University of California, 202 Wurster Hall, Berkeley, CA 94720-2000. (e-mail: kondolf@ced.berkeley.edu)

P. R. Wilcock, Department of Geography and Environmental Engineering, Johns Hopkins University, Baltimore, MD 21218.

(Received December 27, 1995; revised February 15, 1996; accepted March 19, 1996.) 